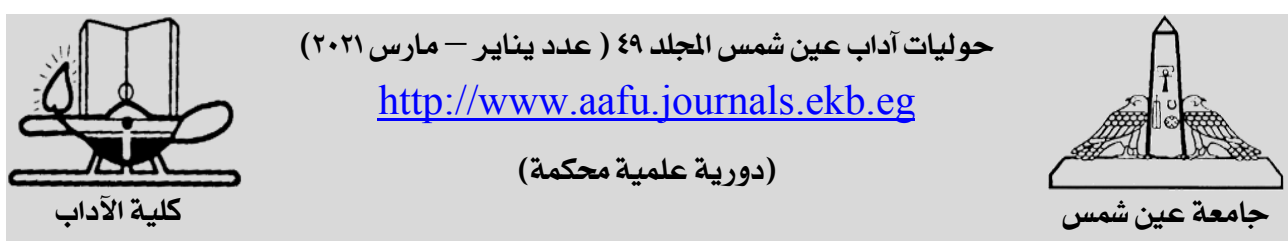

\title{
الفخر بالموهبة الشعرية البارقي نموذجاً
}

مؤيد عباس حسين

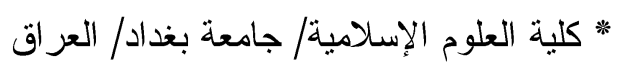

Woh82@gmail.com

لقد انشغلت منذ زمن بعيد بفكرة كانت تراودني بين الحين و الآخر الاو وهي محاولة

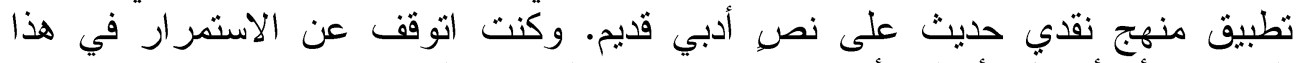

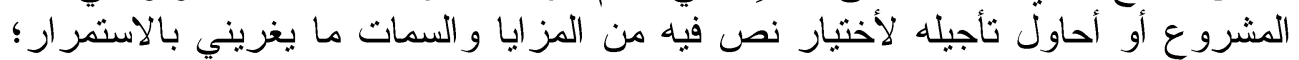

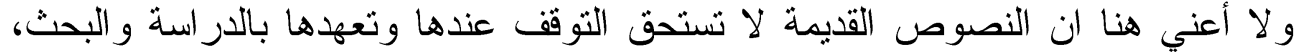

ولكن التقرد و الغزابه هو ما كنت ابحث عنه بالضبط. 


\section{الفخر وأهميته لاى البارقي}

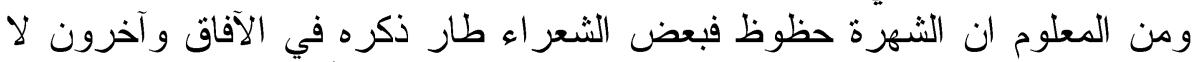

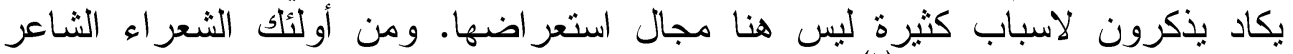

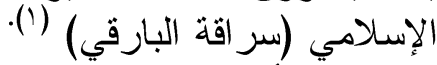

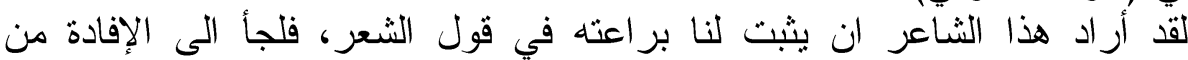

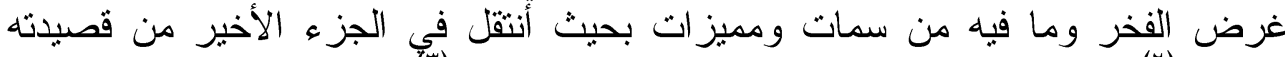

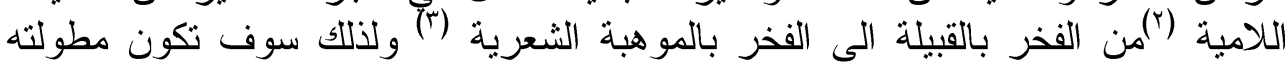

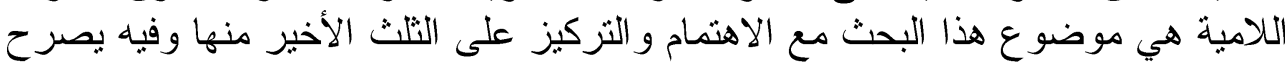

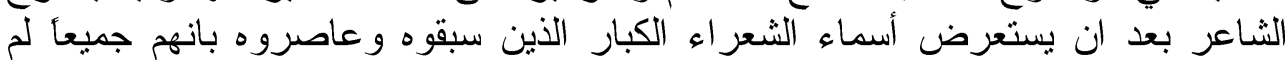
يصلو ا الى ما وصل اليه في سماء الشعر وعو الم البر اعة و التقوق.

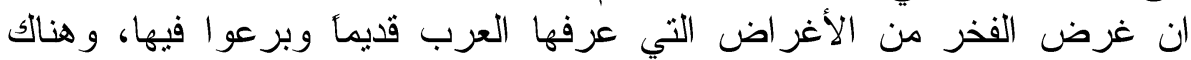

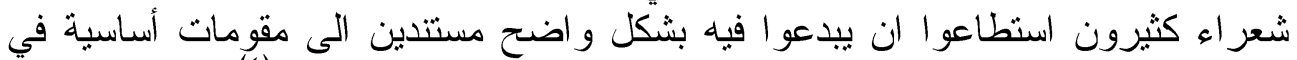

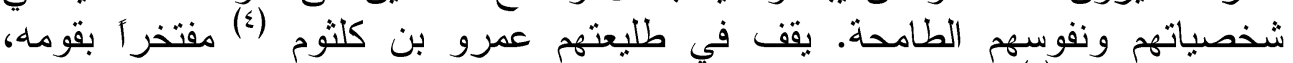
و عنتزه بن شداد (0) مفتخر أ بنفسه.

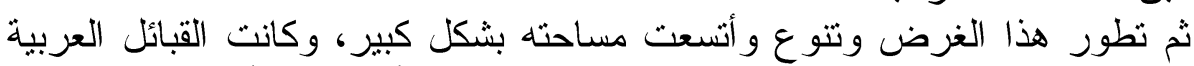

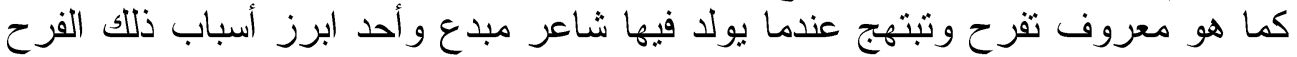

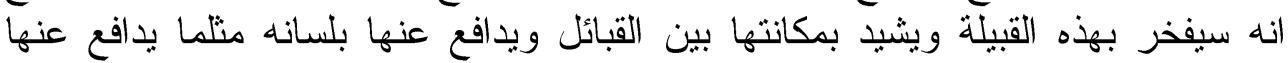
الفرسان بسيو فهر. وجاء الفخر بالنفس بعد الفخر بالقبيلة وغالباً ما يفخر الانسان بشجاعته وكرمه

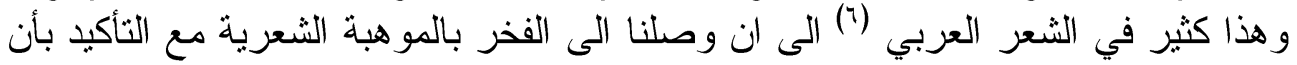

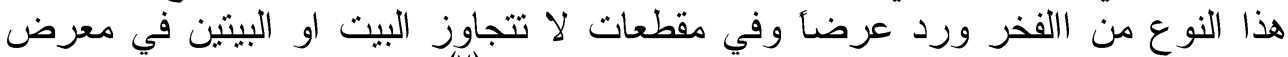

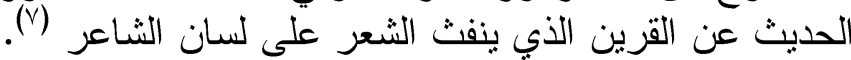

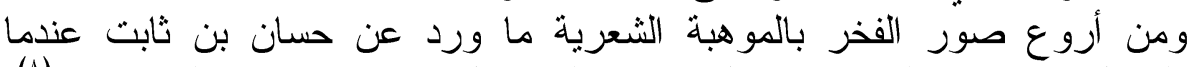

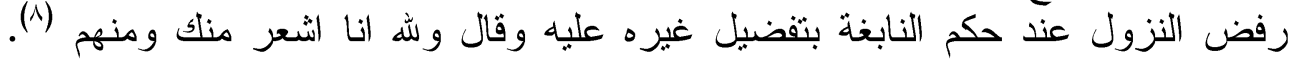
وكان عنترة بن شداد قبله قد اشتكى من ذهاب الصور الجميلة و المعاني الرائعة مع ما فاله

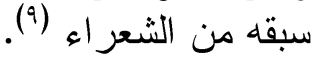

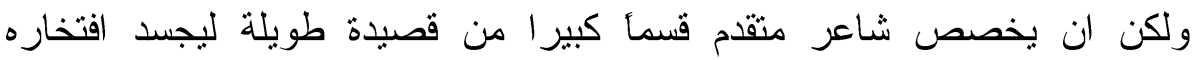
بمو هبته الشعرية، ويتبع كل ذلك تعليلات يحاول ان بجعلها مقنعة معتمدا على ثقافة و اسعة التها

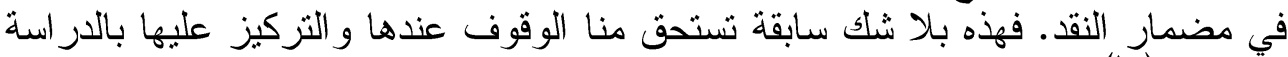
و آلتحليل (·) (1). ان لهذه القصيدة أهمية كبرى في هذا المجال وتلك الأهمية تتبع من جو انب كثيرة

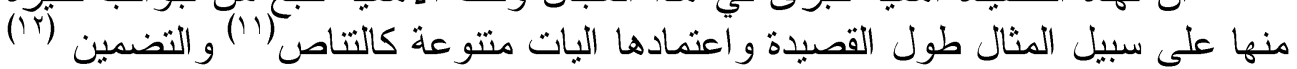

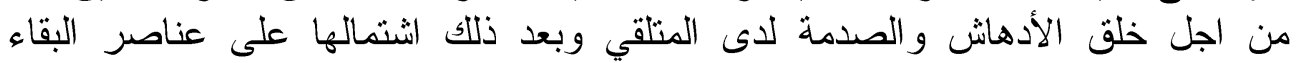

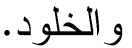

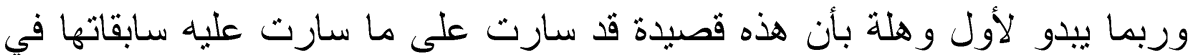

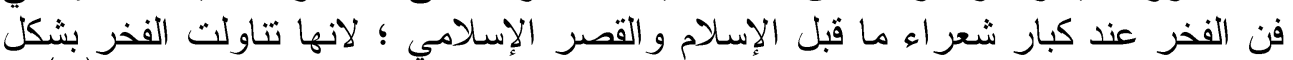

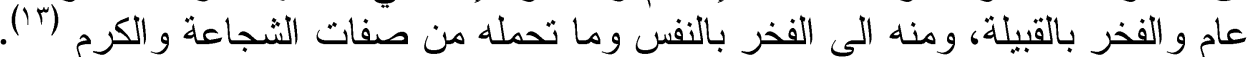
لكنها لم تقف عند هذا الحد بل وققت طويلا امام الفخر بالموهبة الشعرية. في ابيات قاربت ثلث القصيدة هذه الابيات هي التي سوف يركز الباحث عليها ويتعهدها بالبحث 
و الدر اسة لبثبث من خلالها تفوق الثاعر في قدرته وثقافته وسعة اطلاعه على الموروث

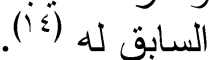

و لا بد لنا قبل البدء بدر اسة هذا الجزء من القصيدة ان تتحدث عن القصيدة بوصفها

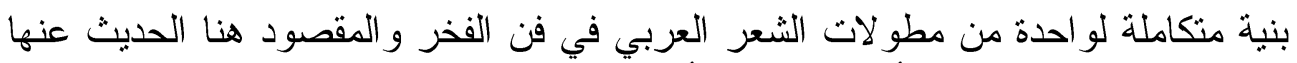
بوصفها قصبدة متكاملة. شأنها في ذلك شأن القصائد الطو ال التي اشتنملت عليها دوو اوين الشعر في ذلك العصدر (10)

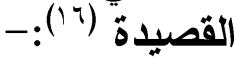

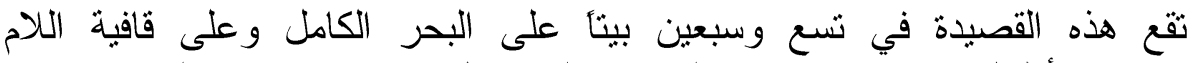

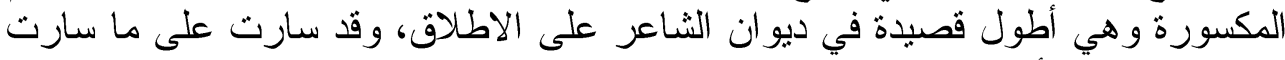

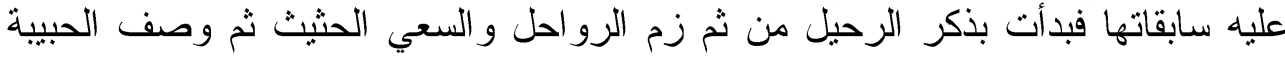

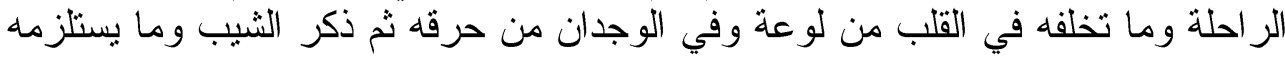

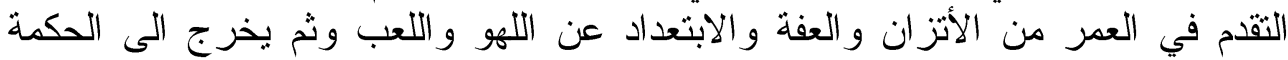

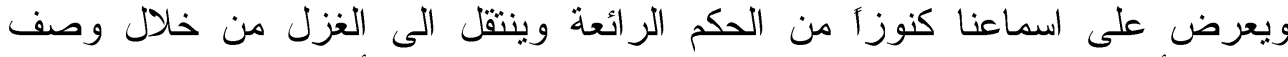
الحبيية بأوصاف طالما تعاورت في دو اووين الشعر اء السابقين فأصبحت قيماً عليا للجمال

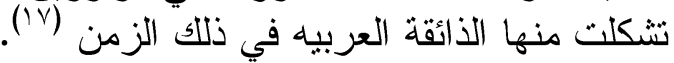

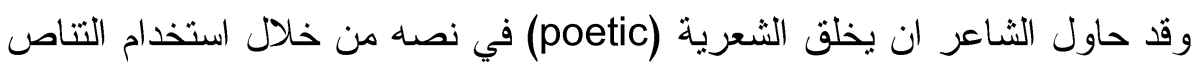

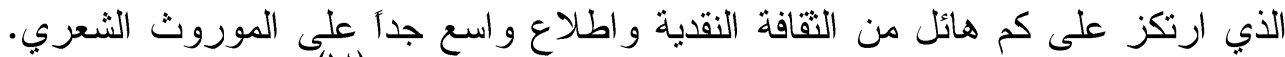

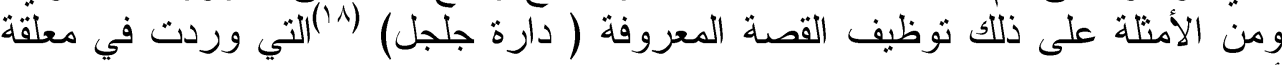

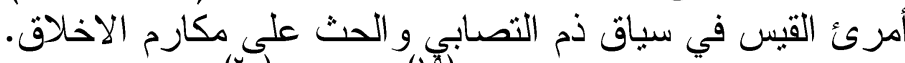

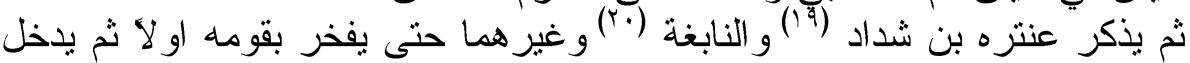

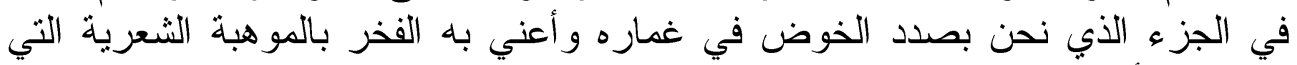
يجزم بان أحدأ من الشعر اء لـ لم يصل اليهاء.

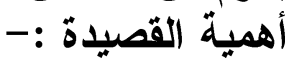

تتركز أهمية هذه القصبدة ومكانتها بكونها تشكف بما لا يدع مجالا للشك مقدار

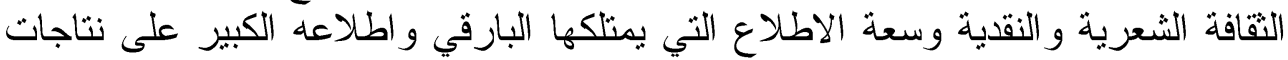

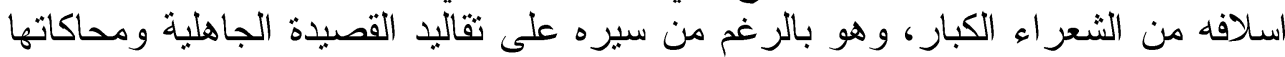

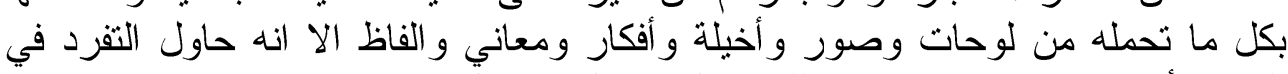

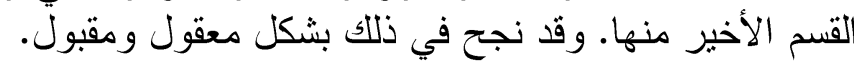

وسوف يستعرض الآن وبشكل سريع ابرز السمات التي اشتملت عليها فئول فيدة.

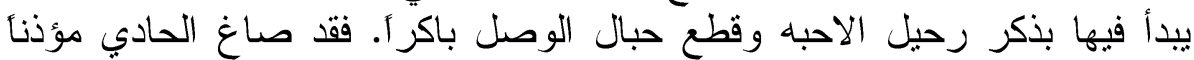

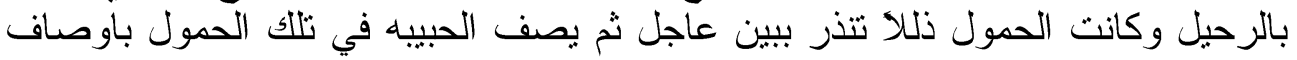

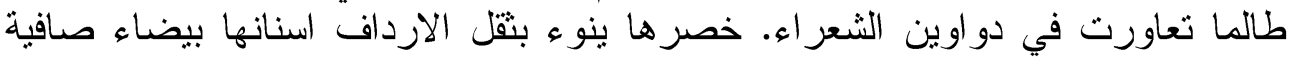

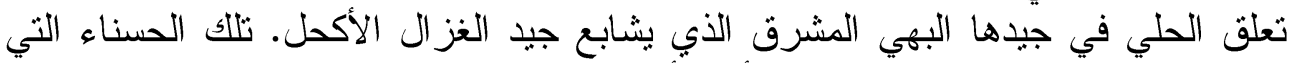

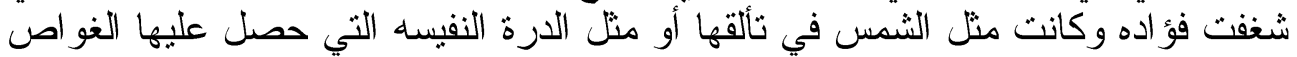

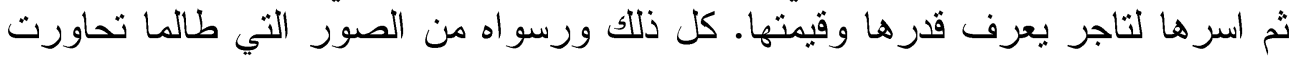

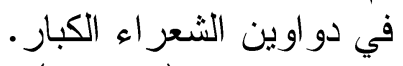

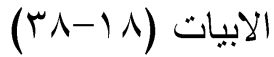


يبدأ في هذه الابيات بتضمين لقصة امرئ القيس التي ذكرها في معلقته عند حديثه

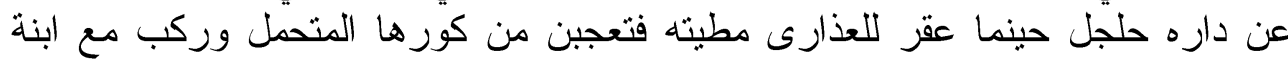

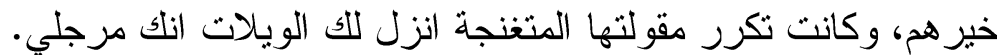
و هنا يستثر شاعرنا هذه الحادثة ويجعل منها بابأ يلج فيه الى عالى عالم الحكمة و الوقار فيقول (r) (r):-

ان لا تصل حبلا اذا لم توصل وارى من الر أي المصيب ثباته

ابــدأ لــذي ضــــن مبــين اقبــلـ و اســتبق ودك للصـــديق و لا نقـــل

واذا هممت بـأمر صــدق فأفعـلـ ودع الفو احش ما اســـنطعت لأهلهــا

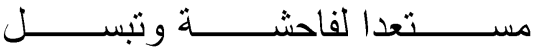
و اذا غضــبت فــلا تكـنـن انشــوطه

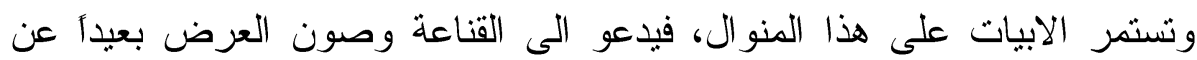

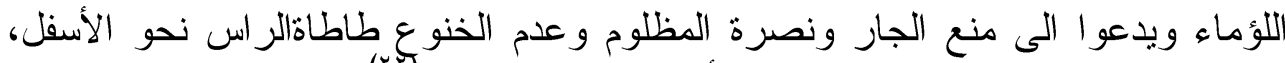

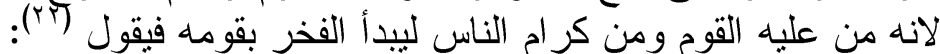

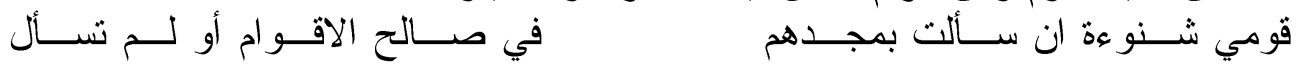

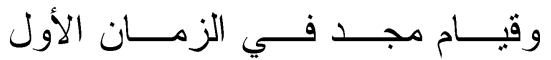
أخبرت عن قـومي بعـز حاضــر

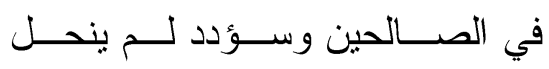

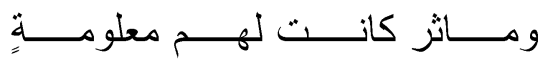
نعم هو من الكرام الذين يرفعون الذم عن احسابهم والذين يكرمون نزيلهم ويطعمون ضيوفهم في ساعة القحط و ايام المحن. وكذلك يحمون الاخيل ويفتدونه بنفوسهر عليهم سيماء المجد التي غلبو فياعة البها. الناس في كل المحافل ، فهم شجعان كرماء فيهر الثاعر المقلق و الخطيب

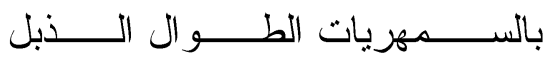

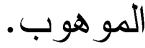

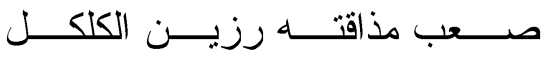

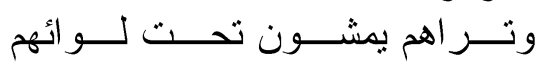

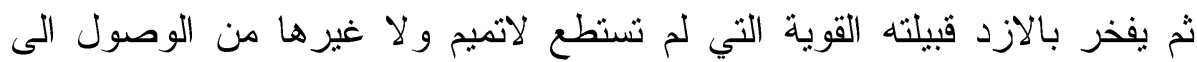

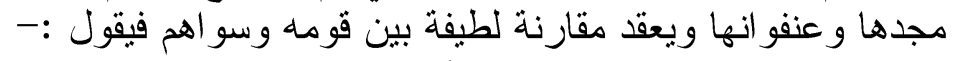

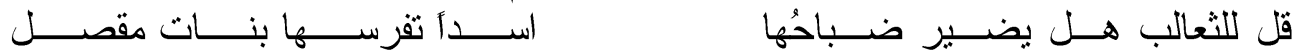

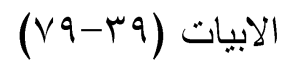

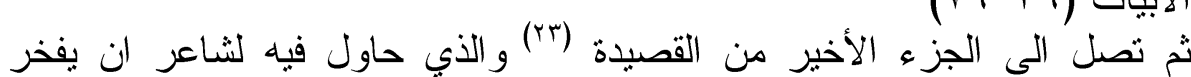

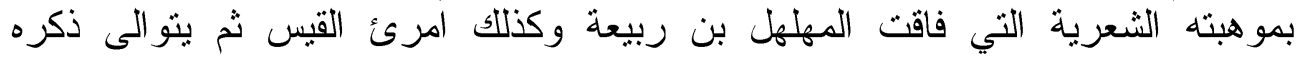

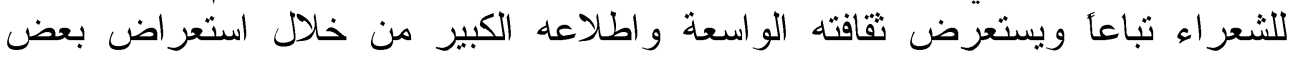
الحقائق و المفاهيم التي تتاولها الدرس النقدي القديم بالدر اسة و الأهنمام ومن تلألك الحقائق

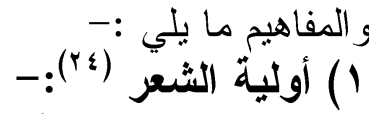
و المقصود هنا بأولية الشعر بدايته وتكاد تجمع المصادر القديمة على ان تلإلك البداية

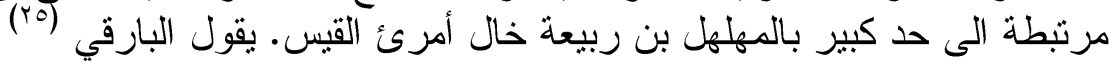




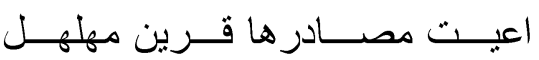

ولقد اصبت من القــربض طرية لئسة

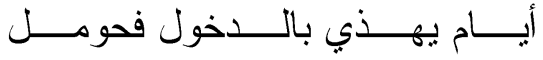

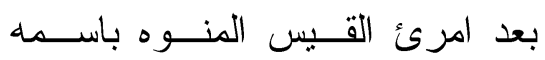

r

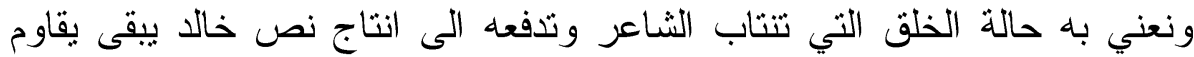

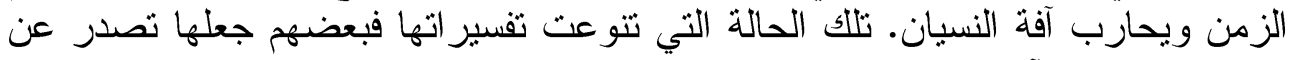

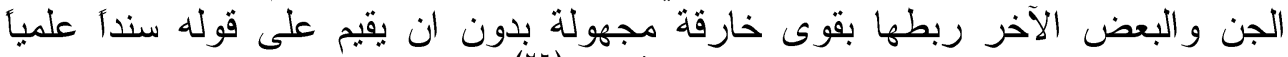

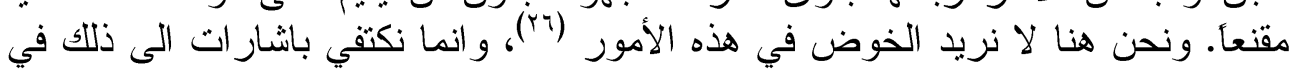
البيت السابق.

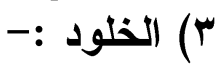

ان استمر ار النص ابرز صفات الجودة فيه وقد لاحظ البارقي بان الثعر الأصيل

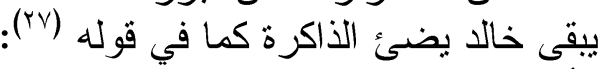

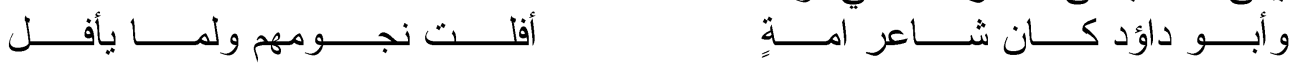

\section{ع) وعورة الألفاظ وصعوبتها :}

من المفاهيم التي انجذب اليها النقد القديم و اشبعها دراسة وتمحيصاً. وقد ناقشها

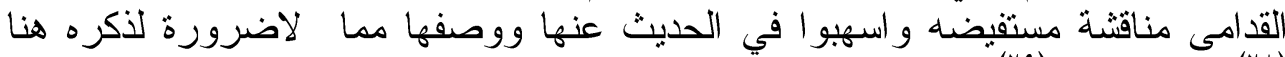
وايقول البارقي(rی)

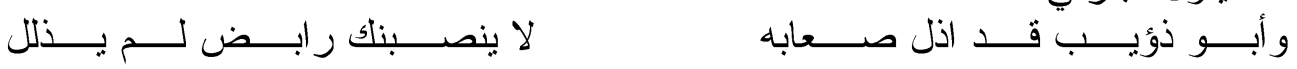

$$
\text { 0) السهولة :- }
$$

سهولة الألفاظ نقيض وعورتها وقها وقسوتها وهنا يذكرنا بلامية حسان في مدح الملك

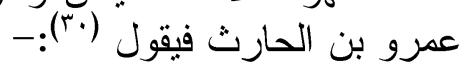

بردى يصــفق بـالرحيق السلسـلـل

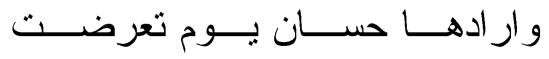
ويردف ذللك بقوله عن عبد الرحمن بن حسان بن ثابت بانه قد سعى مثل ابيه، لكن

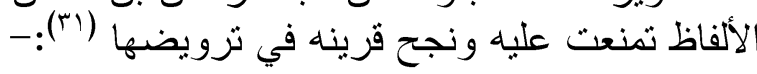

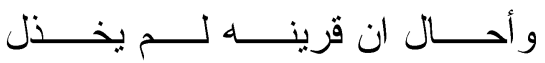

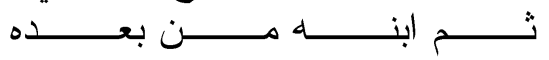

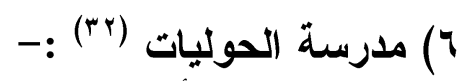

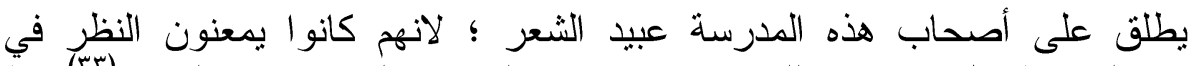

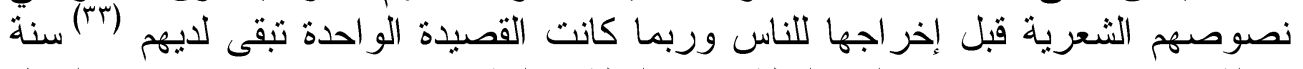

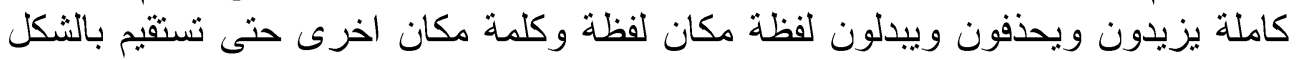

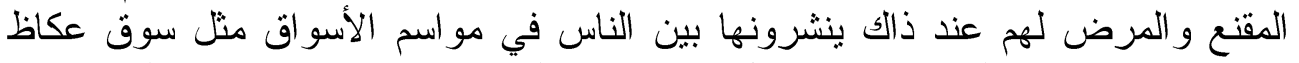

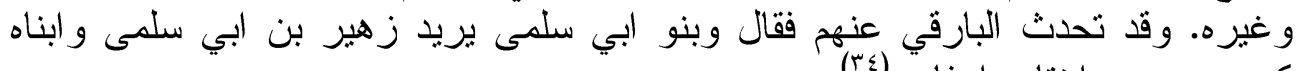
عنا كما قصــرت ذر اعــا جـرول

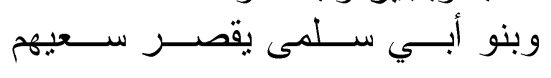
ان الاكثار من قول الشعر ربما يخلق من عدم الانتظام في نسيج الشعر؛ و ولاسيما

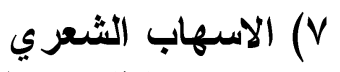

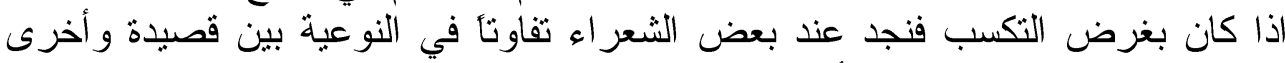

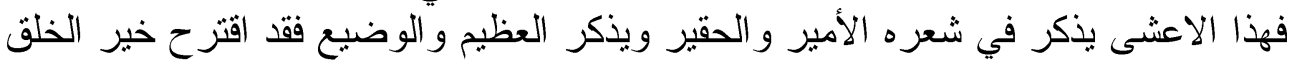




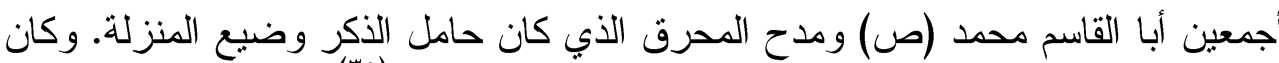

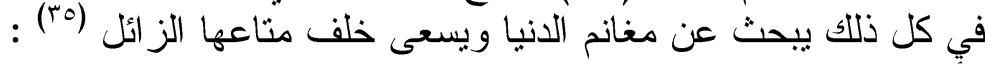

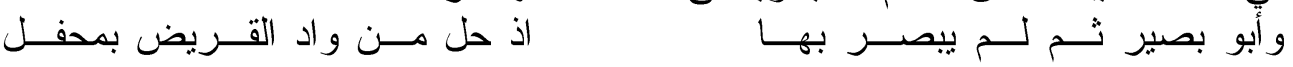

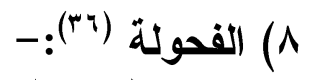

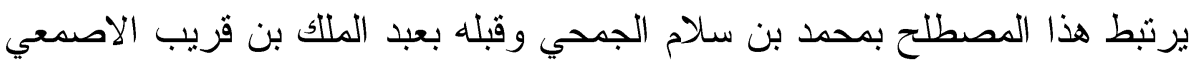

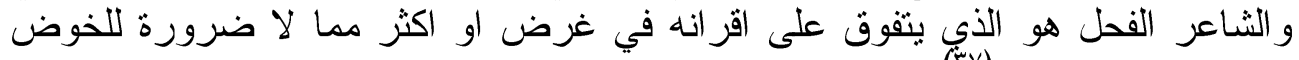

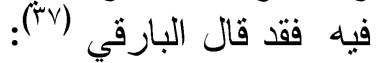
سسيلومك الثــعر اء ان لــم تقعـل و اذكر لبيدأ فــي ألفحــول وحاتمــأ

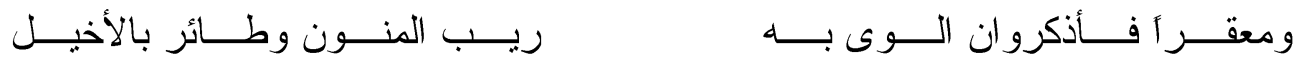

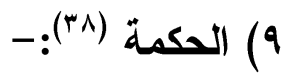

ان من الثعر لحكمة وأن من البيان لسحرا. لقد أعجب العربي بالحكمة أيما

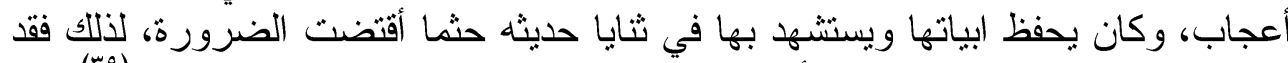

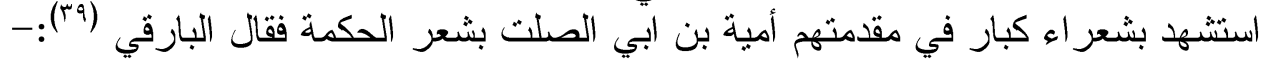

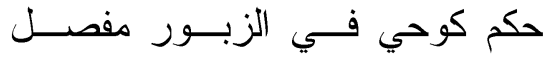

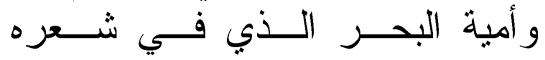

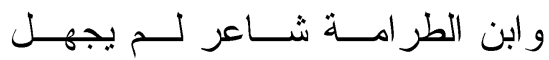
و أقنف انا الطهحان وسط خ وانهــ

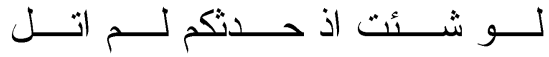

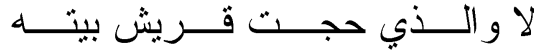
ممــن ســمعت بــهـ و لامســتعجل ما نال بجري مـنهم مسن شــاعر

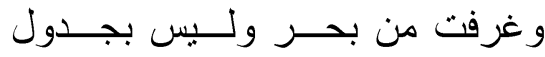

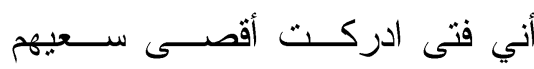

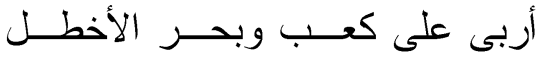

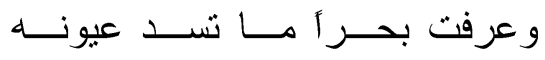

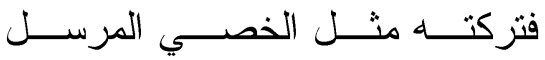

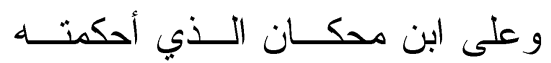

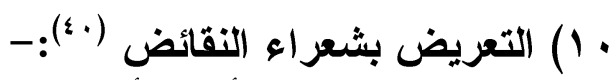

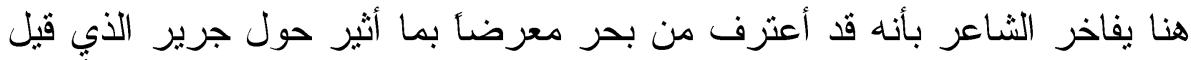

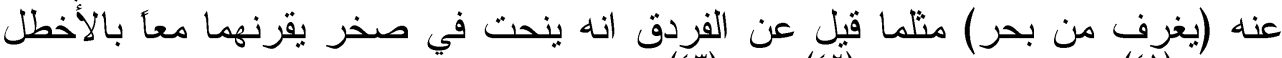

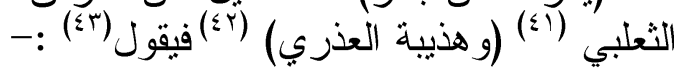
وبـــهـ يعبــر كـل امــر مفصــل وحليف ابلـيس الــني هـــو جـاره

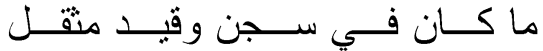

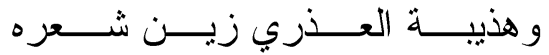

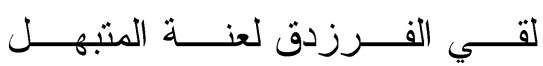

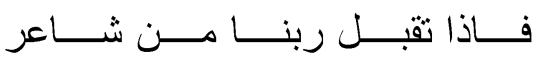

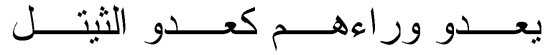

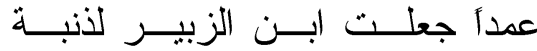
أني كـذلك مـن يناضــل بنضــل

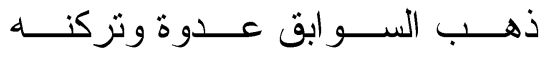

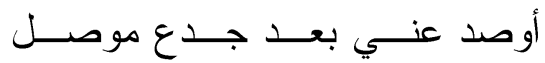

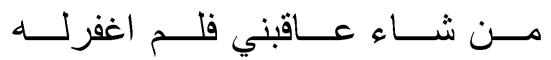


وينتهي النص بصورة دقيقة تكشف لنا بوضوح ثقافة الثاعر وتمكنه من ادواتها،

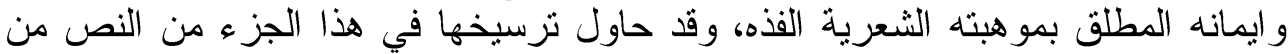

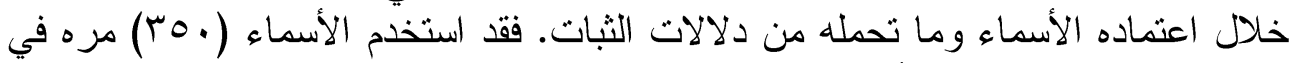

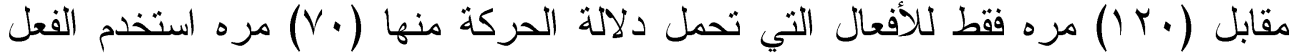

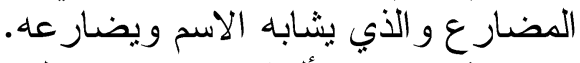
ثم اعتمد الألتفات وتحث مع النفس الضمير المخاطب كما فعل الأخطل في قصيدة

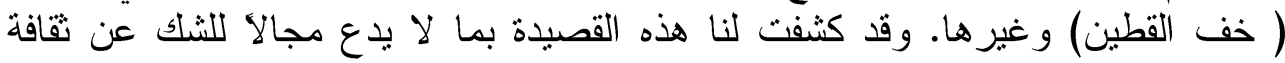

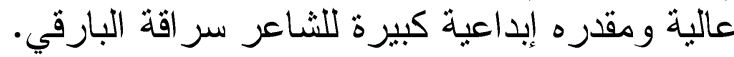




\section{Abstract}

\section{Pride in the bright poetic talent is a model}

\section{By Muayyad Abbas Hussain}

I was long preoccupied with the idea that I had from time to time, which is to try to apply a modern critical approach to an old literary text. I was stopping to continue with this project or try to postpone it to choose a text in which the advantages and features are tempting me to continue؛

الإهو (مش)

(') هو سر اقه بن مرداس بن أسماء بن خالا بن عوف بن عمر بن سعد بن عدي بن حارثه ينظر ديوان

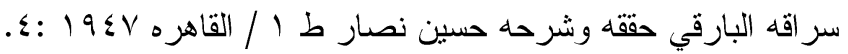

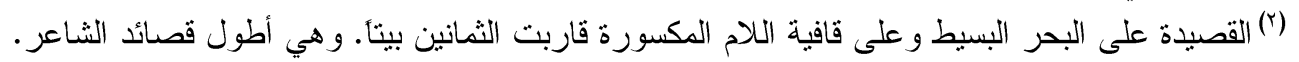

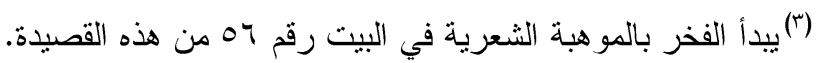

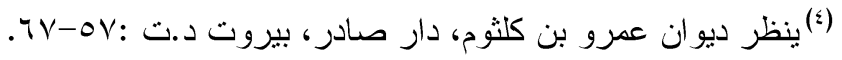

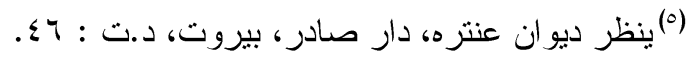

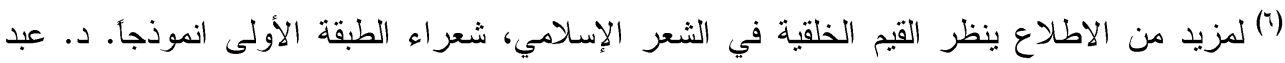

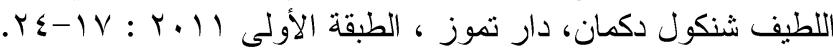

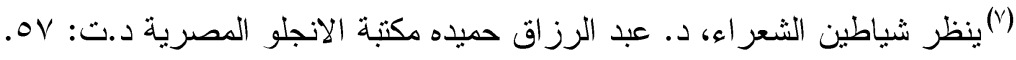

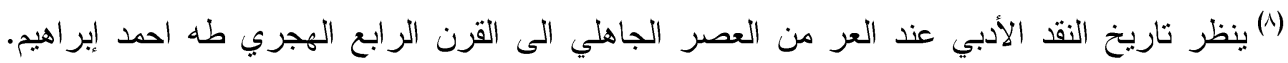

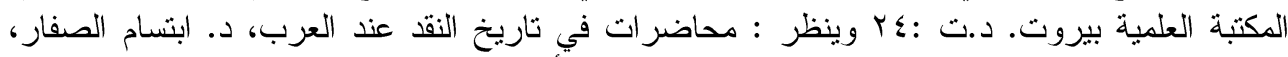

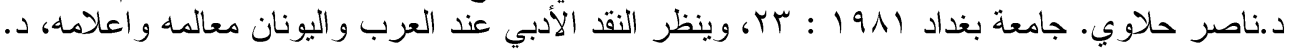

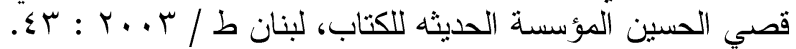

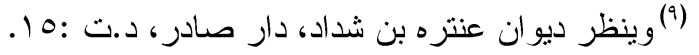

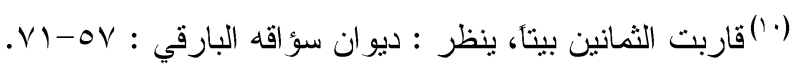

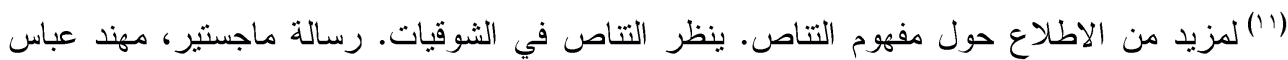

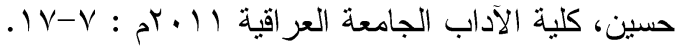
إن

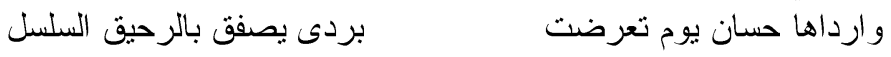

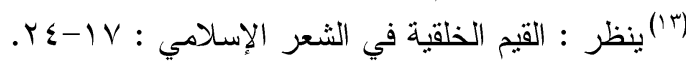

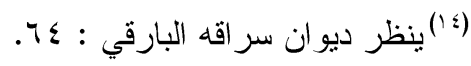

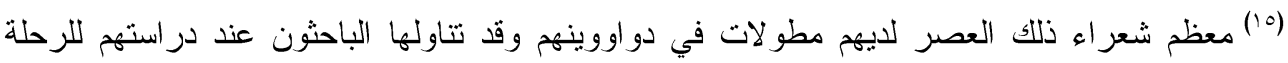

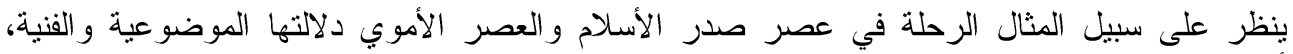

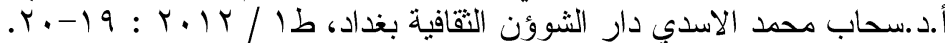

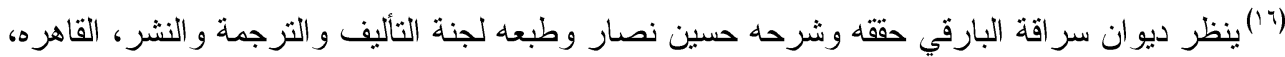
. $V 1-0 V: 19 \leqslant V / 1$ b

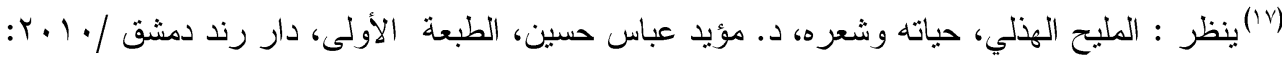


(1) ينظر : ديوان امرئ القيس قدم له وشرحه ووضع فهارسه د. صلاح الدين الهواري. دار مكتبة

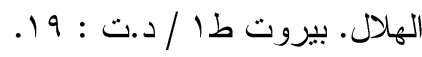
(19) (T)

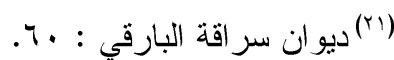

(T)

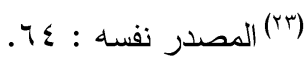

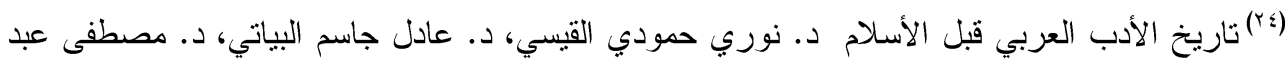

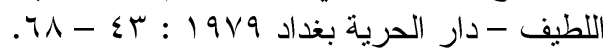

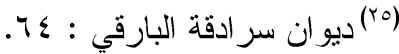
(ب) ينظر في طريق الميثولوجيا عند العرب، حمود سليم الحوت.

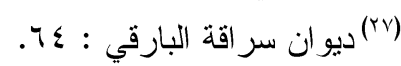

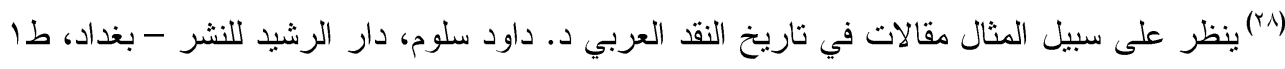
$.1 \times 1: 1911 /$

(ب9)

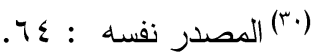

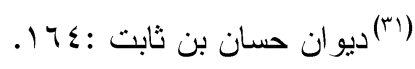
: (r) المصدر نفسه (ف)

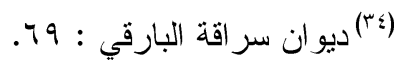

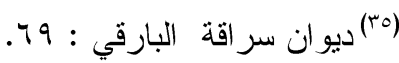

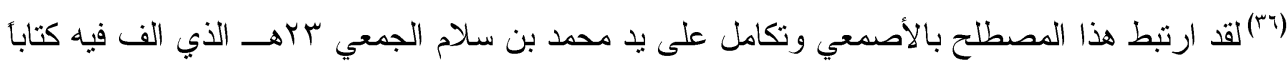
بعنو ان طبقات فحول الشعر اء لشركة دار القدس، تحقيق محمود محمد شاكر . لالأ

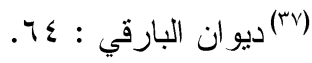

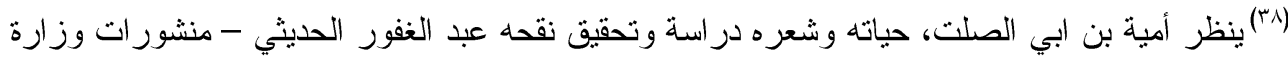

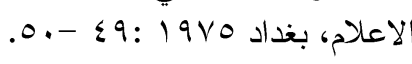

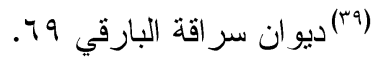

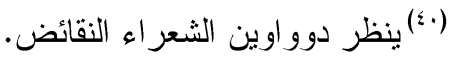

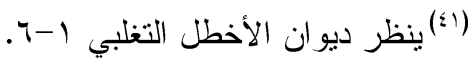
(Y) ينظر : ديو ان الأخطل التغلبي، مقدمة الديوان. 
لمصادر

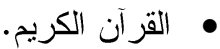

• أمية بن ابي الصلت حياته وشعره، دراسة وتحقيق بهجت عبد الغفور الحديثي، منشورات وزارة

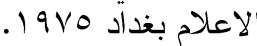

تاريخ الأدب العربي قبل الاسلام. د. نوري حمودي القيسي د. عادل جاسم البياتي، د. مصطفى عبد

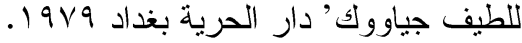
تاريخ النقد الأدبي عند العرب من العصر الجاهلي الى القرن بلد الرابع الهجرب، طه أحمد ابراهيم ، المكتبة العلمية. بيروت دئ د.ت.

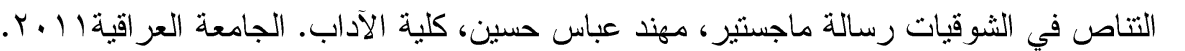

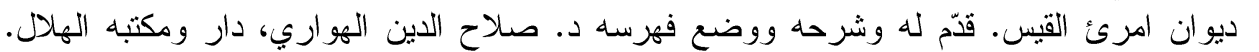

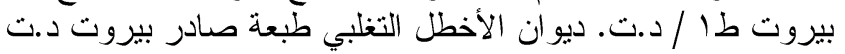

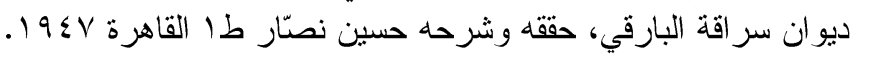

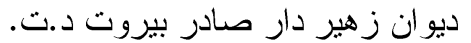

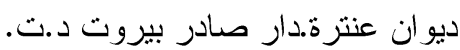

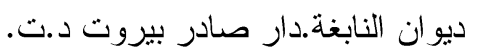

• الرحلة في عصر صدر الأسلام و العصر الأموي دلالاتها الموضورعية و الفنية د.سحاب محمد الاسدي

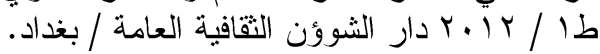

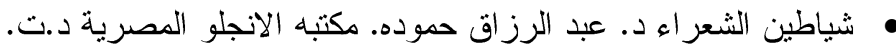

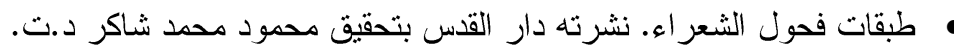

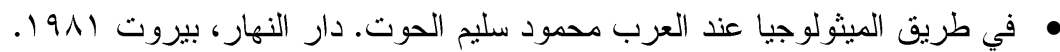
• القيم الخلقية في الشعر الاسلامي. شعر اء الطبقة الأولى انموذجاً د. عبد اللطيف شنكول دكور دكان.دار

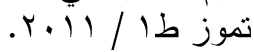

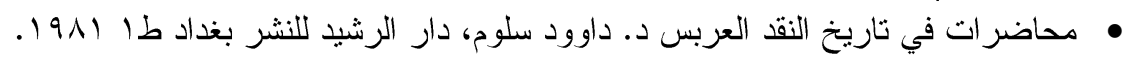

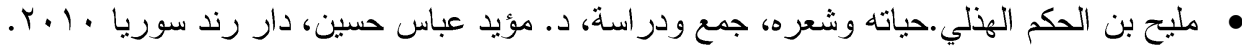

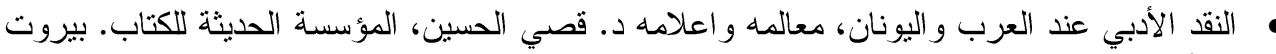

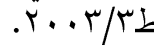

